\title{
Games and the Communication of Ecosystem Services to Non-Scientific Audiences
}

ISSN: 2637-7659

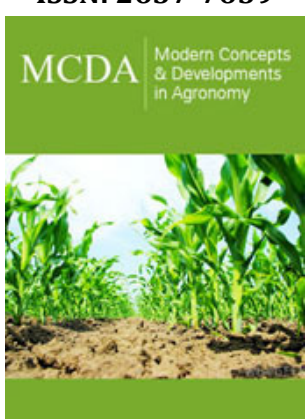

*Corresponding author: Agnieszka Latawiec, Department of Geography and Environment, Pontifícia Universidade Católica, Rio de Janeiro, Brazil

Submission: 制 July 03, 2019

Published: 佔July 17, 2019

Volume 4 - Issue 5

How to cite this article: Agnieszka Latawiec, Marcus Pianura, Ingrid Pena, Lara M Monteiro, Fernanda Gomes. Games and the Communication of Ecosystem Services to Non-Scientific Audience. Mod Concep Dev Agrono.4(5). MCDA.000598.2019.

DOI: 10.31031/MCDA.2019.04.000598

Copyright@ Agnieszka Latawiec, This article is distributed under the terms of the Creative Commons Attribution 4.0 International License, which permits unrestricted use and redistribution provided that the original author and source are credited.
Agnieszka Latawiec ${ }^{1,2,3,4 *}$, Marcus Pianura ${ }^{1}$, Ingrid Pena ${ }^{2,3}$, Lara M Monteiro ${ }^{2,3}$ and Fernanda Gomes ${ }^{2,3}$

${ }^{1}$ Department of Geography and Environment, Pontifícia Universidade Católica, Rio de Janeiro, Brazil

${ }^{2}$ International Institute for Sustainability, Rio de Janeiro, Brazil

${ }^{3}$ Rio Conservation and Sustainability Science Centre, Center of Social Sciences, Pontifícia Universidade Católica, Rio de Janeiro, Brazil

${ }^{4}$ Institute of Agricultural Engineering and Informatics, Faculty of Production and Power Engineering, University of Agriculture in Kraków, Kraków, Poland

\section{Abstract}

Scientific results should also be disseminated to non-scientific audience. Communication and knowledge exchange are, generally, not treated as priority for scientists possibly due to lack of time, interest or reward. There are funds such as Carlos Chagas Filho Foundation for Research Support in the State of Rio de Janeiro (FAPERJ) that require knowledge exchange to non-scientific audiences as a condition for project acceptance. We conducted an environmental education activity through an active learning method in a high school of Rio de Janeiro. The aim of the game was to explain activity concepts of environmental resources management, tragedy of commons, tipping point and reproduction rate. The game was focused on fisheries, but similar concepts are used in the management of other commons such as water, air, and increasingly soils. The activity and the results are presented in a short video.

\section{Introduction}

Dissemination of scientific activities is essential to legitimize the social role of science in the progress of mankind [1]. Communication processes involving a multiplicity of activities aimed at presenting, disseminating, discussing and problematizing science are at the core of this movement. This variety of initiatives encompasses different spaces and communication channels with their own objectives, characteristics and methods focused at the general public, or specific audiences.

Innovative strategies for the dissemination and knowledge exchange are fundamental part of a FAPERJ and Newton Fund/Royal Society funded project called: "Sustaining land from the bottom up: developing a conceptual model for evaluating ecosystem services for tropical soils". The term 'ecosystem services' has become a widely used tool for understanding the linkages between ecosystem functioning and human well-being to inform policy and decision makers [2]. Despite successful initiatives, such as TEEB or IPBES that provide integration among different sectors of society in relation to the benefits offered by nature, ecosystem services have not been extensively incorporated into public and private decision making, especially in some countries, as initially expected [3].

We applied the Fishing Game [4] in a high school of Rio de Janeiro with 65 students as an educational activity about ecosystem services and natural resources management. Games and puzzles represent pedagogical tools that engage participants through excitement and problem solving, wherein participants compete or cooperate with each other in formulating strategies to manage resources [5-9]. The students played the role of fishermen whose aim was to fish the maximum of fish stock possible. The game introduced concepts of the tragedy of commons, tipping point, reproduction and renovation rates, sustainability, maximum sustainable yield and gave the opportunity to analyse human behaviour and need for collaboration. Students were participative and at the end of the activities, most of them showed dissatisfaction with the colleagues who reached higher stocks of fish, although few have actually tried some collaborative strategy. Students' overfishing led to a rapid depletion of fish stocks. Unable to reproduce, fish stocks diminished dramatically and led to a system collapse. When informed about the rates of regeneration and the optimal number of fishes to be taken out from the stock, the students continued playing for their self-interest instead of collaborating. Most students expressed their understanding that the game represents reality. 


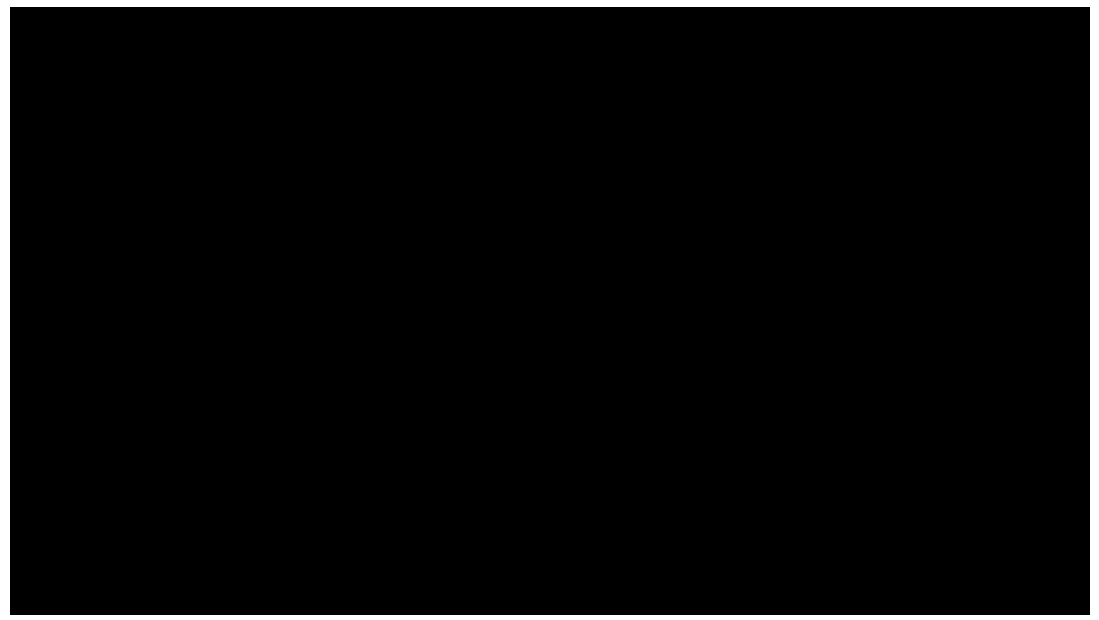

The lack of interest of students in classrooms submitted to traditional teaching methods is something recurrent. The use of a diverse range of educational innovative tools can complement traditional education and provide youth with practical and reallife experiences to apply the scientific method to solve problems [10]. Educational games can contribute to make teaching more interesting for students at the elementary, middle, and higher level or in non-formal educational situations and spaces. Another interesting approach to raise awareness and democratize scientific literacy are citizen-science initiatives. Because they place common citizens as protagonists of the scientific discovery, participatory approaches, such as citizen science, increases the chance of projects succeeding in the long term. They may also bring benefits to local population through empowerment and learning. In the environmental field, public participation in data collection and evaluation can be useful to monitor the state of the ecosystems and natural resources in order to inform better management practices [11]. For example, ecosystem monitoring toolkits and rapid assessment methodologies are already being used to evaluate forest condition, water quality and soil health [12-15].

Over the two-year FAPERJ-and Newton Fund-project on soil ecosystem services, we will apply other innovative communication tools such as behavioural economics games and video co-production to actively engage different stakeholders, including students and land owners. We also aim to apply both gaming and citizen science in other projects related to ecosystem services. For example, in a Global Environmental Facility funded project named "GEF Private AreasConserving biodiversity and rural landscapes" we are developing a methodology of soil quality monitoring in restored areas with local landowners. We aim to produce a replicable monitoring protocol to be used for informing public policy and other scientific projects. We encourage other researchers to communicate their results to a wider audience and to incorporate innovative knowledge exchange tools in their projects.

\section{Acknowledgment}

"Sustaining land from the bottom up: developing a conceptual model for evaluating ecosystem services for tropical soils" is funded by Newton Fund, FAPERJ and National Council for Scientific and Technological Development (CNPq) which are gratefully acknowledged.

\section{References}

1. UNESCO (1999) World conference on science for the twenty-first century: A New Commitment. Budapest, Hungary.

2. Fisher B, Turner RK, Morling P (2009) Defining and classifying ecosystem services for decision making. Ecological Economics 68(3): 643-653.

3. Weyland F (2019) Ecosystem services approach in Latin America: From theoretical promises to real applications. Ecosystem Services 35: 280293.

4. Meadows DH (2008) Thinking in systems: a primer. Earthscan, London, United Kingdom.

5. Siqueira IJ, Antunes AM Jogo de trilha "lixo urbano": educação ambiental para sensibilização da comunidade escolar. Ensino, Saúde e Ambiente. 2013 3(6): 185-201.

6. Joaquim FL, Camacho ACLF (2014) O uso de jogos como estratégia de ensino: relato de experiência. Revista de Enfermagem UFPE Online 8(4): 1081-1084.

7. Kishimoto TM (1994) The game and child education. Perspectiva 12(22): 105-128.

8. Santos AM (2016) Gamificando a educação ambiental: o desafio jogando verde no Instituto Federal Baiano. Revista Brasileira de Educação Ambiental 11(1): 246-263.

9. Carvalho VL, Silva CB (2016) Jogo educativo sobre a saúde coletiva um relato de experiência do processo de ensino-aprendizagem. Revista de Enfermagem UFPE Online 10(6): 2242-2246.

10. Shah HR, Martinez LR (2016) Current approaches in implementing citizen science in the classroom. J Microbiol Biol Educ 17(1): 17-22.

11. Chase SK, Levine A (2016) A framework for evaluating and designing citizen science programs for natural resources monitoring. Conservation Biology 30(3): 456-466.

12. Handford P (2004) FORMAK forest monitoring manual. FORMAK, Paekakariki, New Zealand.

13. Biggs BJF, Kilroy C, Mulcock CM, Scarsbrook MR (2002) New Zealand stream health monitoring and assessment kit. Stream Monitoring Manual. Version 2. NIWA, Christchurch, New Zealand.

14. Tipa G, Teirney L (2003) A cultural health index for streams and waterways: Indicators for recognising and expressing maori values. Ministry for the Environment, Wellington, New Zealand.

15. Nicholls CI, Altieri MA, Dezanet A, Lana M, Feistauer D, et al. (2004) A rapid, farmer-friendly agroecological method to estimate soil quality and crop health in vineyard systems. Biodynamics pp. 33-39.

For possible submissions Click below: 